\title{
ICT Regulation Toolkit to Expand Telecom and E-Services
}

"There is a widespread agreement about the transformational opportunities that ICTs offer to a country's economy. Experience has shown, in turn, that access to ICTs is optimized by countries with effective competition-centered, market-friendly regulatory frameworks that support and sustain both ICT investment and diffusion, and thereby benefit consumers. The right framework is so critically important that it can generate billions of dollars of investment." These are conclusions by the World Bank infoDev in announcing release in January 2009, of a fully revised and expanded ICT Regulation Toolkit, from the earlier handbook.

infoDev further points out, however "implementing such a framework has become more challenging than ever in recent years as the ICT sector continues to undergo major structural changes. Regulators need to manage the transition from old to new ICT environments, which raises a wide range of questions involving some of authority of ICT regulatory institutions, approaches to licensing, competition policy and level playing field in the new environment, what to do about legacy subsidy arrangements, approaches to universal access in order to successfully realize potential of alternative network infrastructures such as WI-FI and WiMAX to bring both services and high speed Internet access to urban and rural areas, and the need to introduce an increased role for market forces in radio spectrum allocation."

The ICT Regulation Toolkit, produced by infoDev and the International Telecommunication Union (ITU) is a much expanded, practical web-based update of infoDev's popular and influential Telecomm Regulation Handbook issued in 2000. The Toolkit is divided into several modules clustered around key themes, it also provides access to more than 200 practice notes drawing from experiences across the globe and over 1000 relevant reference documents from both developed and developing countries. (www.ictregulationtoolkit.org) The ICT landscape has continued to evolve significantly since the publication of the Handbook, improving opportunities and raising new challenges. Many ICT developments will promote greater access to ICTs, especially in developing countries. The Toolkit is divided into seven modules:

"Module 1: Regulating the Telecommunications Sector: Overview. This module describes telecommunications growth and innovation, presents rationale for regulation, principles for effective regulation as well as key success factors and risks of failure.

Module 2: Competition and Price Regulation: Fair competition, interconnection and access, prices and data requirements for effective price regulation are described.

Module 3: Authorization of Telecommunication/ ICT Services: Introduces authorization approaches, competitive licensing processes, authorization practices and special authorization situations.

Module 4: Universal Access and Service: Principles and basic concepts involving market shortfalls and development gaps, including roles of the government and the private sector. Scope of support beyond the market, principles of cost-effective support, funding sources and mechanisms, are presented as well.

Module 5: Radio Spectrum Management: Current trends and technical aspects described including spectrum use issues, the international administrative framework. National institutional arrangements, authorizing spectrum use and assigning frequency bands are reviewed. Other sections examine stakeholders, spectrum pricing, monitoring and enforcement, and capacity building for regulators.

Module 6: Legal and Institutional Framework: Laws and regulations, international treaties and agreements, WTO, national legislation and regulation, institution- 
al arrangements for telecommunications regulation, as well as the regulatory process, relationships with judiciary and competition authorities are examined, as well as human resources and capacity building.

Module 7: New Technologies and Impact on Regulation: New technologies and applications including convergence, the Internet's impact on networks, business models, market structures and regulation, as well as broadband are presented."

\section{Rationale for an Effective and Independent Regulator}

"Effective regulators are normally associated with being to some degree independent. The rationale for establishing independent, often sector-specific, regulatory institutions are based on ensuring nondiscriminatory treatment of all players in the liberalized market. As the outset of the transformation process, the pre-existing monopoly structure allows for discriminatory behavior. The emphasis on non-discrimination arose from four sources which, in part, reflect different constituencies in the market. These four broad necessities are to ensure that:

- cooperation is enabled in a competitive environment where the old structures may be unwilling to cooperate and where prospective cooperation is between unequal cooperators/partners.

- all equipment suppliers are treated equally where the market is dominated by a single buyer with strong pre-existing relationships with suppliers.

- all new entrants and investors in the telecommunications service sector are treated equally by the dominant competitor, who will be a supplier of inputs (e.g. interconnection) to the businesses of new entrants, and

- all customers have a 'voice' and their complaints and interests receive adequate response.

Addressing non-discrimination involves building confidence in and the legitimacy of an 'independent' regulatory institution. The central issue is establishing a functioning, enabling environment (regulator(s) and regulations) that will attract sufficient and sustained investment to satisfy existing demand, expand supply and introduce new services, independence stimulates investor confidence and reduces regulatory risks. The UN Task Force on Financing ICT stated: "the explosion of ICT sector investment in most developing countries correlates closely with an improved environment for private investment to take place and the transformation of formerly closed, monopoly ICT markets to allow competitive entry. Where Governments have actively pursued an open, equitable market environment, investors have generally welcomed the opportunity to compete. The Task Force further observed: The introduction and strengthening of independent, neutral sector regulation has helped to reinforce investor confidence and market performance while enhancing consumer benefits.

The success of competition and private investment is demonstrated in mobile markets in Africa and is demonstrated in the fact that by the end of 2006 the total number of mobile subscribers in 48 sub-Saharan African countries was just 125 million, up from 88 million at the end of 2005. Of these, 123.5 million customers resided in jurisdictions where competition prevailed in the provision of mobile services."

\section{What is the Role of Regulators?}

"Often there are sector specific regulations, general regulations (such as competition authorities) and special agencies or ministries charged with specific tasks (such as spectrum management), that all share common duties. As noted by the UN Task Force, and underscored in this toolkit, the most important duties of regulators include:

- implementing the authorization framework that provides opportunities for new companies and investors to establish ICT businesses. Simple authorization procedures tend to maximize new entry).

- regulating competition (including tariffs) involving the effective enforcement of fair and equitable competitive market principles, restraining the power of dominant suppliers and leveling the playing field for new entrants.

- interconnecting networks and facilities. Normally transparent rules are established for interconnecting all types of traditional and new communications networks and associated cost-based payments.

- implementing universal service/access mechanisms to ensure the widespread (and affordable) diffusion of ICT.

- managing the radio spectrum effectively to facilitate new entrants and new technologies which is particularly relevant to new broadband wireless opportunities such as Wi-Fi and WiMAX.

- minimizing the burden and cost of regulation and contract enforcement. 


\section{Convergence and Regulators}

"Platforms fulfilling different functions have traditionally been regulated differently for many reasons. For example, the telecommunications platform has been regulated in a different manner than broadcasting platform. In the context of convergence, where a single platform is capable of delivering all forms of electronic communications, should separate regulatory bodies merge or remain distinct institutions? Or, should there be one regulator for platforms and other for content?

To date, there is relatively little experience (with some exceptions) of addressing these questions and quite possibly there are more multi-utility regulators (which include telecommunications) than 'converged' regulators. In Malaysia the issue was addressed at an early date. The Communications and Multimedia Act 1998 established the Malaysian communications and Multimedia Commission (MCMC) as the sole regulator of telecommunications, broadcasting and computing industries. However, while the EU is implementing a 'future-proof' single regulatory framework for electronic communications, only four member states out of 25 (as December 31, 2006) have what could be regarded as 'converged' regulatory bodies. These are Finland, Italy, Slovenia and the United Kingdom.

The OECD distinguishes between regulatory bodies dealing with:

- telecommunications,

- broadcasting carriage,

- broadcasting spectrum allocation, and

- content.

Among OECD members, only Australia and Iceland have single bodies dealing with all four forms of regulation. For each of the EU countries listed above, at least one of the four regulatory functions lies outside the 'converged' regulator.

In a converged environment the absence of a converged regulator allows for the possibility of unequal regulatory treatment of different platforms delivering overlapping content or unequal regulatory treatment or different content delivered over any platform. Here there is the issue of technology-neutral regulation, meaning that the regulatory treatment of a particular service, regarding authorization, spectrum, interconnection, universal service, numbering, is the same irrespective of the technology used to deliver it. Convergence poses challenges to both the structure and the instruments they use."

\section{Legal and Institutional Framework}

"The telecommunications sector has undergone extensive changes in recent decades, from a monopoly structure to one of competition, motivated by the evolution of new technologies and services, the growing importance of telecommunications for national economies and the development of international trade in telecommunications services. This module provides an analysis of how countries have undertaken regulatory reform to adapt to these changes and explore the legal and institutional framework necessary for effective regulation. The module is organized along the following lines:

- Introduction - provides a roadmap of the study and overview of the objectives of the module.

- Why Regulate - discusses the need for regulation to ensure the market transition from monopoly to competition and safeguard the public interest.

- Legal Context of Regulatory Reform - provides an overview of different factors that may impact regulation, such as (1) the different legal and cultural traditions of each country; (2) the national and international commitments undertaken by the government, (3) the impact of other legislation that impact the sector and (4) level of maturity of the market.

- Impact of Convergence - examines the impact of convergence on regulation of the sector, analyzing how regulators have responded to convergence with more flexible and streamlined regulatory frameworks and how ICT related laws have impacted the sector.

- Elements for an Efficient Regulator - identifies what it means to be an efficient regulator, and the different dimensions of effectiveness, including structural and financial independence and functionality.

- Organizational and Institutional Approaches to Regulation - provides detailed analysis of the organizational and institutional approaches to regulation, and discusses institutional design options, the separation of power and relationship of the regulator with other entities, the legal status of regulators, their funding process, staffing procedures and ethical conduct.

- Functional Aspects of Regulation - analyzes the regulator's competencies, mandate and regulatory procedures, including decision-making procedures, accountability of regulatory activities, and dispute resolution and enforcement procedures." 


\section{Three Waves of ICT Technological Development}

"The Toolkit presents a mapping of technologies that can assist to identify and classify three waves of ICT technological development leading to fundamental changes in network and industry development. Those three waves can be categorized in the following manner:

- Digital Technologies

- Mobility and Internet Technologies, and

- Application Technologies to Restructure Organizations and Activities

Telecom reform so far has been primarily associated with or in response to the technological changes of the first wave of technological development. The key features of the second and third waves challenge the established regulatory paradigm in a number of ways. Telecom networks are becoming more multifaceted and complex. The end-to-end design of Internet Protocol (IP) networks gives rise to a range of new issues, e.g. VoIP competition, network security, interconnection, and qualify of service (QoS). The moving of network intelligence form the central core of networks to the edges allows many new kinds of ICT services and application providers to become significant market players. It also poses new security risks. End-to-end design means that a whole new range of players can be active in markets, and nevertheless remain outside traditional regulatory oversight and control.

The implementation of second and third generation wave technologies gives rise to the further advanced development of infrastructure networks, including ubiq- uitous networks, the portable Internet, and the automated Internet of communicating objects. Many new technologies are expected to be on a smaller scale and less expensive to deploy. This will change investment cycles and patterns, speed up the introduction of new projects and services, and enhance possibilities for competition. Smaller players will be able to enter markets and fuel network expansion with relatively smallscale investments, if the policies and regulations are not obstructive.

The policies and regulations established in this more multifaceted and complex environment will influence technological trends, affecting the speed, direction and extent of development in different countries. Compared to the relatively simple success criteria of fostering network development through competition and universal access rules that characterized the first wave, regulators will need to establish multidimensional success criteria. The second and third waves introduce major new challenges for policy makers and regulators.

The intersections among major technological developments and traditional areas of regulation must be reexamined in the new environment. For example, traditional price regulation must be re-examined not only regarding the implications of new mobile technologies, such as $3 \mathrm{G}$, but also regarding the combined effects of mobility with the Internet, NGNs and other dimensions of convergence.

The sooner regulators are able to address these challenges, the greater the influence they will have over the development path of the telecom and ICT sectors, and of the information society that emerges in their respective countries. 